\title{
Learning Microbiology Through Cooperation: Designing Cooperative Learning Activities that Promote Interdependence, Interaction, and Accountability
}

\author{
JANINE E. TREMPY,* MONICA M. SKINNER, AND WILLIAMA. SIEBOLD \\ Department of Microbiology, Oregon State University, Corvallis, Oregon 97331-3804
}

\begin{abstract}
A microbiology course and its corresponding learning activities have been structured according to the Cooperative Learning Model. This course, The World According to Microbes, integrates science, math, engineering, and technology (SMET) majors and non-SMET majors into teams of students charged with problem solving activities that are microbial in origin. In this study we describe development of learning activities that utilize key components of Cooperative Learning_positive interdependence, promotive interaction, individual accountability, teamwork skills, and group processing. Assessments and evaluations over an 8-year period demonstrate high retention of key concepts in microbiology and high student satisfaction with the course.
\end{abstract}

The Cooperative Learning Model has garnered support as an effective educational paradigm through which professors serve not just as lecturers but as creators and facilitators of learning environments. Numerous studies, both at the precollege and college levels, support the claim that Cooperative Learning (CL) environments are very effective ( 3,4 , $7,11,13,15,16)$. When applied appropriately CL promotes higher retention of the skills and concepts learned, higher individual achievement, greater intrinsic motivation to learn, more frequent use of cognitive processes, increased retention of students until graduation, and increased building of positive and supportive relationships among diverse students than did competitive or individualistic learning $(3,4,7,11$, $13,15,16)$.

What is Cooperative Learning? Cooperative Learning is often mistaken for Collaborative Learning. Both involve learning environments that rely on groups of students. However, the manner by which learning takes place within these teams is fundamentally and mechanistically different. D. Johnson and R. Johnson describe CL as a "learner-centered instructional process involving small, intentionally selected groups of students who work interdependently on a well defined task," such as a problem to be solved (8). There are five essential components to CL: positive interdependence, promotive interaction, individual accountability, teamwork skills, and group processing $(6,8,10-13)$. In order for CL to be effective, each of these components must be clearly addressed. Students are individually held accountable for learning and participating, and cooperation is absolutely necessary for success. CL is not students sitting together and discussing while working individually on assignments (i.e., collaborative learning). Furthermore, it is not students doing individual projects or assignments with the instructions that the ones who finish first are to help the other members of the group. And finally, it is not assigning a task to a group of students and having only a few members of the group work on the task, while the others contribute nothing yet reap the

\footnotetext{
*Corresponding author. Mailing address: Department of Microbiology, Nash Hall 220, Oregon State University, Corvallis, OR 97331-3804. Phone: (541) 737-4441. Fax: (541) 737-0496. Email: trempyj@orst.edu.
}

glory and the credit $(4,8,9,11)$. Thus, CL does not just involve student discussion groups but rather involves highly integrated, interdependent, task-oriented teams.

If Cooperative Learning is effective, then a prediction can be made that as support for this educational paradigm increases, its use will become more popular. This prediction holds true for the social and liberal science disciplines. In contrast, for the biological disciplines, the least effective and/ or least inclusive teaching methods (competitive- or individualistic-based learning) still predominate, especially at the precollege and college levels $(1,2,14)$. One obstacle to applying the CL paradigm to science courses has been the availability of appropriate learning activities that fully embrace the components of $\mathrm{CL}$, yet provide the perceived rigor of a traditional lecture-test course. Previously, a microbiology course has been described that integrates upper-division science, math, engineering, and technology (SMET) majors and non-SMET majors into teams of students charged with problem solving activities utilizing CL (17; J. E. Trempy, Abstr. 98th Gen. Meet. Am. Soc. Microbiol., abstr. H-172, 1998). In this study we describe course structure and learning activities that fully utilize the essential components of CL.

\section{METHODS}

Course structure: MB390, The World According to Microbes. The MB390 microbiology course integrates SMET and non-SMET majors into teams of students charged with problem solving activities that are microbial in origin (17; Trempy, Abstr. 98th Gen. Meet. Am. Soc. Microbiol.). This course structure is summarized and presented as a timeline of benchmarks and corresponding actions (learning activities) in Fig. 1, based on a 10-week academic quarter with 80 students. Each team of students is assigned a contemporary global problem in which microbes are either the cause or the solution. The problem is relevant and controversial and has multiple components and outcomes. Four students from different academic disciplines are assigned to a team. Each member of the team is assigned the role of an expert in a field relevant to the problem. Students are assigned a role for which they have very little background. After clearly defining each student's responsibility so that no one 
Students identify appropriate references.

Benchmark 1: Students develop an outline with references for their expert role using questions asked of them in the scenario.

Benchmark 2: Students synthesize at least three pages of information corresponding to their outline.

Benchmark 3: Team members meet to develop an integrated composite script consisting of synthesized information from all experts. An instructor facilitates the process.

Benchmark 4A: Students develop PowerPoint slides for their expert role based on the composite script. These slides are synthesized before the next team meeting.

Benchmark 4B: Team members meet to integrate and assemble their PowerPoint slides into one complete presentation. An instructor facilitates the process. Recommendations are synthesized at this meeting.

Benchmark 5: Team members present their findings to the rest of the class. Team members answer questions from the audience and defend their recommendations.

Benchmark 6: Each student prepares questions for the other presenting teams and writes a content summary and evaluation of the other 19 presentations.

Benchmark 7: Each team member synthesizes a final written report with cited references. Students answer selected questions put forth by the class.

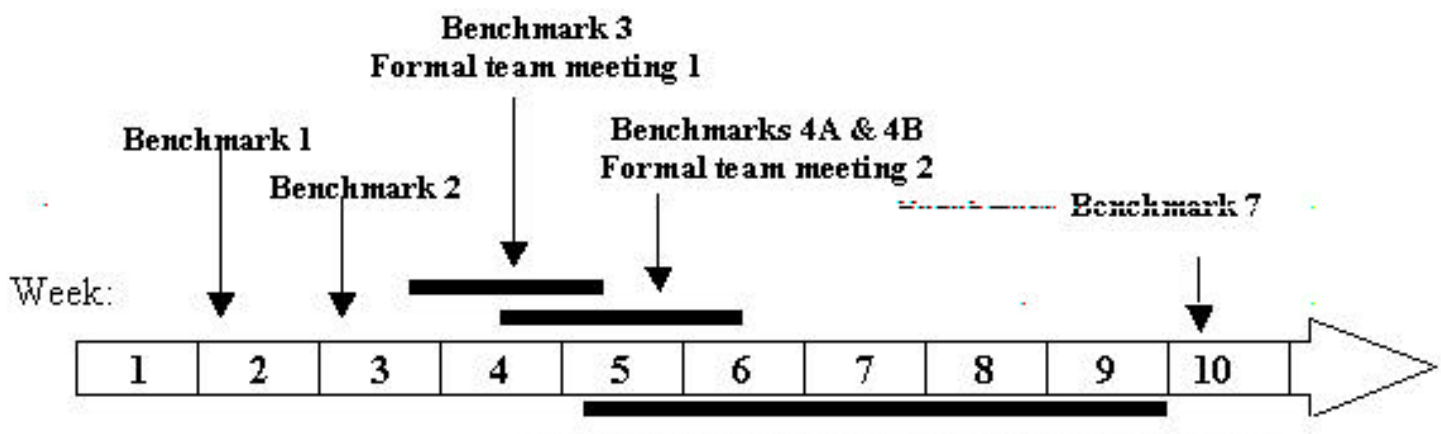

Team PowerPoint presentations (Benchmarks 5 \& 6)

FIG. 1. Timeline of benchmarks and corresponding actions (learning activities) for MB390 and used in Cooperative Learning. This timeline is based on a 10-week academic quarter with 80 students per course section. Twenty teams of four students per team work on 20 different microbial problems with 80 unique expert roles.

person on a team is doing all of the work, and there is no duplication in the expectations of the expert roles, the students set out looking for relevant information to use in an outline (Benchmark 1). At this point, information gathering is limited only by a student's imagination. If necessary, students are shown how to gather and interpret information from a wide variety of resources, including traditional science journals, books, and the Internet. Students are shown how to find, contact, and properly interview experts in the relevant fields, including scientists, health care professionals, engineers, lawyers, business leaders, government policy makers, state officials, members of advocacy groups, etc. After collecting, assimilating, and interpreting information relevant to their expert role, each student prepares a written document detailing their findings, including supporting references (Benchmark 2). After this document has been synthesized by the student and checked by the professor, the team members meet to teach each other their various areas of expertise and develop an integrated composite script in an instructional process that is learner centered (CL-driven) rather than professor centered (Benchmark 3). The professor acts as a facilitator at these team meetings and occasionally assists in verifying or correcting information, but it is the responsibility of the students to instruct their team members. Since each team member is assigned a different expert role, and each role is needed to analyze and potentially solve the problem; each student inherently is being held individually accountable for participating, teaching, and learning. It is during these team meetings, after each member has acquired an understanding of each other's expertise, that the team members attempt to solve their real-world microbial problem. Their solutions are synthesized as professional recommendations, and the standard they are asked to achieve is that the recommendations be as logical, realistic, and insightful as possible. The team is required to integrate pertinent information from the four areas of expertise and to synthesize (Benchmarks 4A and 4B) and deliver (Benchmark 5) a public presentation to the other teams and anyone else from the public who is interested in the topic. The presentation is another example of a learner-centered instructional process, because each team is held responsible for educating the other students in the course. After each team presentation, members of the nonpresenting teams prepare questions for the presenting team to answer (Benchmark 6). Then a debate is held, during which the presenting team must defend their recommendations. Very often this debate becomes quite passionate and heated, thus exposing students 
to the emotional intensity that science often evokes. Finally, each team puts together an integrated final written report, including written answers to questions generated from their public presentation and debate (Benchmark 7). These questions have been collected and screened by the instructor.

Cooperative Learning activities may comprise the entire course or a portion of the course. However, in all instances the Cooperative Learning activities will need to promote positive interdependence, interaction, and individual accountability. The Benchmarks, actions (learning activities), timeline, and grading criteria are defined by the course's learning outcomes, content, length, size, and student demographics. Relevant questions include the following. Are the learning outcomes content based or skill based or a blend of both? Is the microbial content at the introductory or advanced level? Is the length of the course a 10 -week term or a 15 -week semester? Is the course enrollment large or small? Are the students seniors or freshmen? Are they microbiology, engineering, or non-SMET majors? These considerations will factor into the structure of a course utilizing Cooperative Learning. For example, the learning outcomes for the Cooperative Learning MB390 course have been influenced by the university's Baccalaureate Core Curriculum Committee. The learning outcomes for this course are skill based, rather than content based, and require the use of synthesis, integration, critical thinking, analysis, and communication skills (written, verbal). The microbial content, although important, provides the framework in which to use these skills. The course length is a 10-week term and the class meets twice per week. The average enrollment is 80 students per course section (20 teams consisting of four students per team). Because the only prerequisite for MB390 is to be of junior or senior standing, the student demographics vary from section to section and year to year. This strongly influences the level of the content used in the Cooperative Learning activities. For example in Fall 2001, the course was 10\% SMET majors and $90 \%$ non-SMET majors, with only $5 \%$ having had a previous microbiology course. Twenty percent were honors students while $35 \%$ were academically at risk. For many of the teams in the Fall 2001 course, none of their members were SMET majors. Because of the demographics (i.e., very little previous knowledge of microbiology) and the length and size of the course, 20 different microbial problems were used, involving 80 different expert roles, with each team responsible for one of the problems and its four corresponding expert roles. The teams delivered their final PowerPoint presentations to the rest of the class in an order that reflected the level of difficulty of the microbial content; the most difficult microbial problems were presented toward the end of the course. Grades were determined based on individual contribution so as to maintain accountability. No group grades were given. Assessments of each Benchmark and corresponding action, and a final assessment for content retention comprised the grade. A student's individual final grade was based on completion of the following benchmarks: identify references and develop an outline (Benchmark 1), 5\% of final grade; expand the outline (Benchmark 2), 10\%; develop an inte- grated composite script (Benchmark 3), 5\%; develop PowerPoint slides (Benchmark 4A), 10\%; develop an integrated PowerPoint presentation (Benchmark 4B), 5\%; present and defend the report (Benchmark 5), 5\%; prepare questions and a summary for the other 19 presentations (Benchmark 6), 20\%; prepare the final report and answers to questions (Benchmark 7), 10\% and 15\%, respectively; and complete the final assessment to determine content retention, $15 \%$. The course instructors previewed PowerPoint slides for accuracy of content during meetings with individual students or at the second team meeting. All written activities were graded for each student. Criteria used for grading written activities were based on the expectations of the course, namely the use of synthesis, integration, critical thinking, and analytical skills, and included finding, using, and citing reliable, verifiable references (synthesis); developing content related to the expert role (synthesis); accurately presenting content (synthesis); using correct grammar and having a clear and flowing presentation; integrating individual content with other team members' content (integration); and accurately answering questions posed by peers and course instructors (analytical skills and critical thinking).

Developing cooperative learning activities. Central to CL is the development of learning activities that promote positive interdependence, interaction, and individual accountability. We have discovered that the design of the team's project is central to achieving effective CL. Project design requires careful and reflective consideration. The professor must first define the learning outcomes so that the projects used in the course reflect these predetermined learning goals. Second, the professor must recognize that the way the project is crafted will strongly influence the student's approach to the problem both at the global and expert-role levels. The project is the student's portal of entry into the necessary research and, as such, will provide the first keywords, researcher's names, and other clues that will give the student a viewpoint from which to start searching for resources and information.

Projects are designed as "scenarios." A scenario is a welldefined issue that makes an argument requiring or allowing examination. All scenarios are microbial in origin; the microbe is either causing the problem or can be used to solve the problem. It is important that the team members begin their research with a well-defined mission, otherwise four independent paths of research are likely to remain independent, with no content available to promote interdependence and interaction. Thus the mission is designed in such a way that it is apparent there is a need for all experts on the team to participate (i.e., individual accountability).

There is a precise structure to each scenario. It consists of a narrative, controversy, global objectives, and individual expert roles. The two scenarios in Fig. 2 provide an example of this structure. The scenario in Fig. 2A describes an infectious disease and biosafety issue entitled "And, we used to worry about nuclear melt downs!" The expertise needed to address this issue includes an Infectious Disease Specialist, Public Health Epidemiologist, Physical Plant and Facilities 
Administrator, and University Biosafety Officer. The scenario in Fig. 2B describes an environmental and energy issue entitled "Manure Happens." The expertise needed to address this issue includes an Anaerobic Microbiology Specialist, Alternative Energy Resource Engineer, Agricultural Economist, and Environmental Specialist. The narrative of a scenario presents the microbial issue and controversy, some of the issue's historical and social relevance, and keywords as a frame of reference (especially needed by non-SMET majors who have not taken any other microbiology course). The first one-third to one-half of the scenario is written in a general narrative style. A human element should be introduced early in the scenario so as to provide relevance. As the narrative develops, additional information is given to provide keywords for students to use in their research. The narrative moves toward a specific objective, controversy, or issue. This development culminates in the definition of global objectives that specifically focus the team members and give shape to their tasks. The global objectives represent the unique mission with which the team has been charged. For a four-member team there will be four interdependent but nonduplicating global objectives each corresponding to the students' expert roles. The global objectives relate specifically to the introductory narrative. The creation, definition, and assignment of expert roles relate specifically to the global objectives. The expert roles define what is expected of individual team members, including a list of questions that, when answered, may assist them in acquiring an understanding of their expertise so that they can teach the others on their team and in the course. Expert roles must be related to the issue at hand but must not set up a situation where two or more team members are responsible for the same information. Additional examples of microbial problems and corresponding expert roles are described in Table 1.

The design of the scenario is essential to achieving the learning outcomes for this CL-driven course. Benchmarks and corresponding actions (Fig. 1), such as finding acceptable references, developing an outline, synthesizing corresponding information, developing an integrated composite script, developing PowerPoint slides and an integrated PowerPoint presentation, and synthesizing recommendations, represent checks and balances to promote interaction, account for individual contribution, and assess learning effectiveness. These Benchmarks are flexible and substitutable with other types of actions, depending on the type of course and the learning outcomes.

Team assembly. Assembling an intentionally selected team takes careful thought on the part of the professor. Teams that can productively work together to develop strategies for analyzing the assigned problems are essential to the effective use of CL methods in a course. In order to build teams, it is helpful to uncover as much information as possible about the students who have registered for the class. For example, a curriculum profile of each student, which does not include confidential information such as grades, can be obtained from his/her academic advisor. Information such as major and minor(s), courses taken, and courses left to take, can all be used to determine the educational demographics of the students comprising the course. Academic advisors are an excellent resource and should be enlisted in the team assembly process. They often have additional information about the enrolled students, such as their career goals, hobbies, and intramural collegiate activities.

The most important philosophy that the professor must apply to team assembly is one that puts team success and productivity as a priority. Information used to assemble teams should be that which will realize the highest level of success and productivity for each team. There are several questions to ask when assembling teams. Has the student taken a microbiology course? Is the student a science or nonscience major? If the student is not a science major, what is the student's major? If the student is not a science major, what science courses has she/he taken? Is the student at the sophomore, junior, or senior level? Does the student know the other students on the team for which he or she is being considered? Are the team members balanced with respect to their career goals and extracurricular activities?

Although team assembly is not a talent, it does require the ability to recognize certain human attributes. For example, it is human nature to select situations that are familiar, such as joining a team consisting of familiar members. This selfselection leads to segregated teams consisting of members with similar backgrounds or interests. We experienced first hand that homogenous teams are a prescription for disaster in a CL-driven course. We have found that the most successful and productive teams are extremely heterogeneous, consisting of members who do not know each other, who pursue different academic majors (ideally only one SMET major per team), and who provide an equal distribution of genders and academic levels (e.g., sophomore, junior, or senior). It is important for students from different backgrounds to have an opportunity to work together and learn from each other's perspectives and strengths. When preassembling teams, the professor does have to allow for some flexibility. If a student drops the course leaving a team short-handed, the first option is to go to the waitlist and complete the team with a different student. If no one is on the waitlist, it may be necessary to have a team with one fewer member, requiring the remaining members to divide the responsibilities of the fourth expert role.

\section{RESULTS AND DISCUSSION}

How do the MB390 course structure and activities integrate the five components of Cooperative Learning-positive interdependence, promotive interaction, individual accountability, teamwork skills, and group processing? To achieve positive interdependence, the learning activities must be structured in such a way that each team member's efforts are absolutely required, and learning outcomes are very clearly defined. This interdependence must be structured, with no duplication, so that successful promotive interaction will take place. There are several ways to establish positive interdependence based on goals, rewards, resources, or roles $(6$, 
For decades, the United States had only two major Biosafety Level 4 high containment laboratories that handled dangerous viruses, both operated by the U.S. government. The Biosafety Level 4 laboratories (BSL4) were the U.S. Army Medical Research Institute of Infectious Diseases (USAMRIID) located in Fort Detrick, Maryland, and the Centers for Disease Control and Prevention (CDC) located in Atlanta, GA. Recently, however, additional facilities have been built in Texas, Canada and at Georgia State University in Atlanta. Three more are planned (all to be located in Texas). The newer BSL4 facilities are not being commissioned by the U.S. government. They are being planned, financed and built by universities whose researchers claim they require these laboratories to attract new research grants and top-notch faculty. Researchers point to the ever-increasing potential for bioterrorism and future outbreaks of deadly scourges such as the Ebola virus as justification for building these Biosafety Level 4 high containment laboratories. "There are so many threats out there," says David Walker of the University of Texas Medical Branch (UTMB) in Galveston, TX, whose Board of Regents have just given the go-ahead to build its own BSL4 facility. "And CDC and USAMRIID really don't have time for every one of these viruses." The UTMB laboratory should be built and open for business by the year 2002. In addition, a laboratory run by the USDA, located on Plum Island, an island in the ocean barely two kilometers from New York city, is seeking permits to upgrade its laboratory facility to a BSL-4 facility. It will be used to investigate viral diseases of animals, such as Nipah viral induced disease. Understandably, there has been communty suspicion and opposition to the granting of permits necessary to operate a BSL-4 laboratory planning to harbor deadly viruses for which there are no known cures or vaccines. A BSL-4 laboratory in Toronto was completely built and ready to open in 1996 when public outcry, supported by input from Hollywood through its movie "Outbreak," prevented the facility from gaining the necessary use permits from the Canadian government. Public suspicion is not altogether unwarranted, as demonstrated by the accidental release (and subsequent cover-up) of unsterilized laboratory waste water (containing pathogenic bacteria and viruses) into the city of Winnipeg's sewage system just a few years ago. Now this controversy may come home to your community. Recently, microbiology research scientists at OSU have been potentially funded to study a very pathogenic virus, the Monkey-B virus, for which there is no cure or no vaccine. One of the main objectives for this project will be the development of a vaccine. Funds for the construction of a BSL-4 facility at OSU has also been potentially approved by the federal agency funding this project. Research on this virus is warranted given the fact that the state of Oregon operates one of four primate centers in the U.S. Furthermore, BSL-4 microbes, such as Monkey B virus, have the potential to be used as biological weapons by bioterrorists, given that there is not cure or vaccine. Obviously, high-ranking OSU Research Office Administrators along with Public Health Officials are concerned about campus and community safety. They have charged your team with the mission to prepare a report in which your team will make recommendations as to: 1) whether or not the U.S. population is at risk of infection by the Monkey B virus, thus justifying research in the area of BSL-4 vaccine development at OSU, 2) whether or not there is a need for a BSL-4 facility at OSU for both the hypothetical Monkey B viral research and other research programs investigating bacteria or virus requiring BSL-4 facilities, 3) how OSU will prepare the campus and the community at large for a BSL-4 level facility, and 4) the type of regulations and safety precautions that will be in effect to protect both campus and community members. The information in your report will be used both by Oregon State University and State of Oregon Officials to debate the feasibility of undertaking the objective to house a BSL-4 facility. Your recommendations must be carefully thought through, taking into account all repercussions if your recommendations are put into effect. Your recommendations must be supported by published scientific reports and published laymen's opinion.

Team Liaison: please name a member from your team

A. Infectious Disease Specialist: Responsible for a report describing Monkey B virus, its biology, its pathology, mode of transfer and infection, and how it is diagnosed clinically. Is a vaccine available for this virus? Why or why not? Does the U.S. currently harbor any samples of this virus for research purposes? If so, then where, if not, then why not? If Monkey B viral vaccine development were to be pursued at OSU, would this research need to be conducted in a BSL-4 facility? Why or why not? Name the other bacteria and viruses that would have to be examined in a BSL-4 facility? Do any scientists at OSU currently work with microorganisms that should be contained in a BSL-4 facility? You will be responsible for gathering the necessary information so that the team may make recommendations as to the need for a BSL-4 facility at OSU for both the hypothetical Monkey B viral research program and other research programs investigating bacteria or virus requiring BSL-4 facilities. In addition to your two page written report, you will be responsible for including a written introductory statement and a summary of the team's final recommendations as to: 1) whether or not the U.S. population is at risk of infection by the Monkey B virus, thus justifying research in the area of BSL-4 vaccine development at OSU, 2) whether or not there is a need for a BSL-4 facility at OSU for both the hypothetical Monkey B viral research and other research programs investigating bacteria or virus requiring BSL-4 facilities, 3) how OSU will prepare the campus and the community at large for a BSL-4 level facility, and 4) the type of regulations and safety precautions that will be in effect to protect both campus and community members. The introductory and summary statements should be prepared as a group effort, with you acting as the recorder of the statement. Any member of your group may present these statements in the team's presentation.
Narrative:

History

Human

element

Keywords

Relevant Issues

Controversy

Global

objectives:

Specific
team
mandate

Expert roles defined:

Specific missions for individual

team members 
B. Public Health Epidemiologist: Responsible for a report describing the history of outbreaks attributed to the Monkey B virus and related members of this family, including the number of people that were afflicted and/or died, and the sociological and economical impact these epidemics had on human societies. Is the U.S. population at risk for infection by the Monkey B virus and other emerging infectious viruses? Why or why not? What are the symptoms of an infected individual? What are the treatments for an infected individual? Is the survival rate high or low? Why? Is the development of vaccines against emerging infectious viruses of vital importance? Why or why not? You will be responsible for gathering the necessary information so that the team may make recommendations as to whether or not the U.S. population is at risk of infection by the Monkey B virus and other emerging infectious viruses, thus justifying research in the area of vaccine development at OSU.

C. Physical Plant and Facilities Administrator: Responsible for a report describing a BSL-4 facility and the regulations in place for this operation of this facility. What are the specifications for this facility? What regulations exist for research conducted in this type of facility? Who will have access to this facility? What are the required safety precautions for a BSL-4 facility? What type of building codes and permits will be needed for this facility? Whose approval will be needed before this facility may be built? Whose approval will be needed before this facility will be used? Who will pay for this facility? You will be responsible for gathering the necessary information so that the team may make recommendations as to the type of regulations and safety precautions that will be in effect to protect both campus and community members.

D. University Biosafety Officer: Responsible for a report describing how OSU will prepare the campus and the community at large for a BSL-4 facility, what will be done in the event of an "outbreak", and the methods and strategies that will be used for disseminating information in a way that will satisfy the public's sense of security. Who will be responsible for overseeing that all precautions are taken to prevent an "outbreak" at the BSL-4 facility? How will inspections of the BSL-4 facility be conducted? How will the public be kept informed as to the activities at the BSL-4 facility? Who will be responsible for informing the public? How will the BSL-4 facility be protected from break-ins? You will be responsible for gathering the necessary information so that the team may make recommendations as to how OSU will prepare the campus and the community at large for a BSL-4 level facility.

Using the information you have gathered as a team, all of you will develop a set of recommendations evaluating:

\section{1). Whether or not the U.S. population is at risk of infection by the Monkey B virus, thus justifying} research in the area of BSL-4 vaccine development at OSU, 2). Whether or not there is a need for a BSL-4 facility at OSU for both the potential Monkey B viral research and other research programs investigating bacteria or virus requiring BSL-4 facilities, 3). How OSU will prepare the campus and the community at large for a BSL-4 level facility, and 4). The type of regulations and safety precautions that will be in effect to protect both campus and community members. The information in your report will be used by Oregon State University and State of Oregon officials to debate the feasibility of undertaking the objective to house a BSL-4 facility.

\section{Global objectives}

\section{Reiterated to emphasize team mission}

FIG. 2A. Scenario structure: components integrated to create a team learning activity based on an infectious disease and biosafety issue.

$10,12,13)$. For this upper-division undergraduate microbiology course, positive interdependence is achieved using nonduplicating expert roles. Each team member is assigned a unique expert role, and the expertise of each team member is absolutely required to analyze and potentially solve the multifaceted microbial problem. For each expert role, the expectation is different, yet the contribution is necessary for the analysis of the microbial problem.

Promotive interaction can be accomplished through learning activities that require team members to integrate their information. In this course, team members are required to integrate pertinent information from their four areas of expertise and create at least three tangible products during promotive interaction: (i) an integrated composite script for their public presentation, with each team member contributing written information; (ii) an integrated PowerPoint presentation, with each team member contributing slides; and (iii) an integrated final written report. Promotive interaction is absolutely required to successfully complete all three assignments. Several formal and informal team meetings are sched- uled outside of class so team members may facilitate each other's efforts toward the group's goal of synthesizing the integrated assignments. Other learning activities can be substituted, including developing an integrated Web page or preparing for content-driven assessments.

Individual accountability measures are often an afterthought when using team-driven learning activities, especially in medium to large size courses where the overwhelming goal is to just manage all of the teams. However, it is an aspect of CL that must be carefully considered so as to prevent teams from stalling in their attempts to achieve their Benchmarks. In this upper-division course, where 80 students represent the average class size, individual accountability is structured several ways. First, teams are limited to four members. Second, individual accountability is thoroughly discussed with students, including a continuing discussion of the way the required Benchmarks and corresponding actions (Fig. 1) serve to encourage individual accountability. Third, group grades are not assigned. Rather, the grading system is based on individual contributions, thus ensuring individual accountabil- 
Manure happens...

July 18, 2001: WASHINGTION (AP) - "Consumer prices edged up last month as electricity prices continued to surge..." Such news stories, shadows of the energy crisis of the seventies, have become prevalent in the media of the early twenty-first century. Once again we are reminded of the non-renewable nature of a hydrocarbon based energy policy, and the quest for alternative energy sources has regained attention. Since the 1980s, hope for developing economically feasible alternative energy sources has centered on solar, wind or nuclear power, all which have limitations or problems. In the 1990s researchers began studying an additional possible renewable energy source based on the production of methane (a combustible gas) from organic wastes such as livestock manure. Central to the process is the anaerobic digestion of the manure by bacteria. The idea has gained momentum recently. The Wisconsin Electric Power Co. said recently that it will begin purchasing power from a facility being built near Shawano, Wisconsin that uses cow manure to help generate electricity as part of its growing renewable-energy program. Methane production plants are becoming more common in the country's dairy states. Carl Theunis's herd of dairy Holsteins in Wrightstown, Wisconsin reportedly produces enough manure that, when microbially converted to methane, over four hundred watts of electricity can be generated, enough to power as many as one hundred homes. The technology is also popular in Denmark, where much of the early development work on biologically generated methane as an alternative energy source was done. According to The National Council for Science and the Environment (NCSE) and the USDA's Natural Resources Conservation Service, conversion of large amounts of livestock manure into combustible methane gas is considered to be an effective method of managing these waste products. However, despite the apparent success and growing popularity of manure based energy production, important questions, such as the economic feasibility, remain. Conscious of both the high cost of electricity and the environmental impact of Oregon's large dairy operations, the Oregon Department of Agriculture and Department of Energy has commissioned your team. They have charged you with the mission to prepare a report in which you will make recommendations evaluating: 1) the physiology and biology of the specific anaerobic microorganisms utilized in the degradation and conversion of manure into combustible methane gas, 2) the state of the art of generating methane from livestock manure from an engineering perspective, including examples of the technology currently being used (worldwide), and an explanation of how such methane production systems work, 3 ) the economic feasibility of the technology, especially with respect to the ability of individual dairy operations to incorporate the technology, 4) the advantages and disadvantages of the technology with respect to the broader range of environmental concerns surrounding dairy farming. Your recommendations must be carefully thought through, taking into account all repercussions if your recommendations are put into effect. Your recommendations must be supported by published scientific reports and published laymen's opinion.

Team liaison: please name a member from your team

A. Anaerobic Microbiology Specialist: Responsible for a report describing the physiology and biology of the organisms used in the anaerobic generation of methane from livestock manure. Include in your report a complete description of the relevant microorganisms and their role in converting manure to methane. Is a single type of microbe involved in the conversion of manure to methane, or is it accomplished by a diverse collection of microbes? Are these naturally occurring microbes, or are they genetically engineered? Where are these microbes normally found? What is the normal role for these microbes in their natural habitats? Can this microbe based technology be effective on a large-scale regional basis? You will be responsible for gathering the necessary information so that the team may evaluate the physiology and biology of the specific anaerobic microorganisms utilized in the degradation and conversion of manure into combustible methane gas. In addition to your two page written report, you will be responsible for including a written introductory statement and a summary of the team's final recommendations evaluating: 1) the physiology and biology of the specific anaerobic microorganisms utilized in the degradation and conversion of manure into combustible methane gas, 2) the state of the art of generating methane from livestock manure from an engineering perspective, including examples of the technology currently being used (worldwide), and an explanation of how such methane-production systems work, 3) the economic feasibility of the technology, especially with respect to the ability of individual dairy operations to incorporate the technology, 4) the advantages and disadvantages of the technology with respect to the broader range of environmental concerns surrounding dairy farming. The introductory and summary statements should be prepared as a group effort, with you acting as the recorder of the statement.

Any member of your group may present these statements in the team's presentation.

B. Alternative Energy Resource Engineer: Responsible for a report specifically describing the process of converting livestock manure to methane from an engineering perspective. What type of facilities would house this technology? What type of equipment would be needed for this technology? What exactly is a bioreactor? Is this technology a reasonable alternative energy source for large population areas? What are some examples of this technology? How do they work? What percent of our energy needs might be met by anaerobic bioreactors producing methane if the technology becomes widespread? Can large population centers be powered by rural bioreactors of this type? Are anaerobic bioreactors likely to replace solar, wind or nuclear energy sources as the dominant alternative energy source? Why or why not? You will be responsible for gathering the necessary information so that the team may evaluate the state of the art of generating methane from livestock manure from an engineering perspective, including examples of the technology currently being used (worldwide), and an explanation of how such methane-production systems work to create energy. 
C. Agricultural Economist: Responsible for a report describing the economic feasibility of converting livestock manure to combustible methane gas by microorganisms. In addition, you should explore the possibilities of forming rural farm cooperatives who could pool resources and produce cattle/methane energy conversion plants. How much would it typically cost to set up an anaerobic microbe based bioreactor to produce methane from manure? Can this microbe based energy generating technology be profitable? How much manure does a single dairy cow produce every day? How many cows make up a herd in a typical dairy operation? How much does it cost to dispose of the manure? Would it be more fiscally prudent to convert manure in to energy rather than dispose of manure through traditional waste management methods? What loans or grants may be available to farmers to build a manure converting center for the production of energy? What financial resources (grants and loans) are available from local, State or Federal governments? Are there private sources of funding available to agriculturists who wish to develop this technology? You should investigate the potential for small dairy operations to form "energy cooperatives", and generate their own energy. Are regional energy providers, such as Wisconsin Electric Power, required to generate a percentage of their energy using alternative sources? You will be responsible for gathering the necessary information so that the team may evaluate the economic feasibility of the technology, especially with respect to the ability of individual dairy operations to incorporate the technology

D. Environmental Specialist: Responsible for a report describing the benefits and negative aspects as it relates to the environmental impact of a microbe based facility that converts manure to energy. Additionally, contrast and compare the microbe based technology to traditional methods of manure disposal as it relates to environmental concerns. Is there an environmental liability, either short or longterm, hidden in the microbe based technology? What do farmers do with the manure that is produced on their dairy farms? What are the environmental issues with respect to the way manure is currently disposed of? Which approach to dealing with manure is more environmentally friendly? Are there laws regulating the way manure is disposed of? If so then how enforces the regulations? You will be responsible for gathering the necessary information so that the team may evaluate the advantages and disadvantages of the technology with respect to the broader range of environmental concerns surrounding dairy farming.

Using the information you have gathered as a team, all of you will develop a set of recommendations evaluating: 1) the physiology and biology of the specific anaerobic microorganisms utilized in the degradation and conversion of manure into combustible methane gas, 2) the state of the art of generating methane from livestock manure from an engineering perspective, including examples of the technology currently being used (worldwide), and an explanation of how such methane-production systems work, 3) the economic feasibility of the technology, especially with respect to the ability of individual dairy operations to incorporate the technology, 4) the advantages and disadvantages of the technology with respect to the broader range of environmental concerns surrounding dairy farming.

\section{Global objectives}

\author{
Reiterated to \\ emphasize \\ team mission
}

FIG. 2B. Scenario structure: component parts integrated to create a cooperative learning activity based on an environmental microbiology (bacterial) issue.

ity. Instructors for this course assess individual contributions in several ways. These include observing the activities of the team, having each student teach the other students on their team and in the course what they have learned, requiring each team member to prepare written assignments and PowerPoint slides related to their expertise, having each team member contribute to the integrated script and PowerPoint presentation and verbally participate in the public presentation, requiring each student to listen to the other team presentations and submit written questions to other presenting teams, and individually assessing each student's understanding and retention of the microbiology concepts at the end of the course through an unannounced "pop" test.

Students, especially SMET majors, have been conditioned to learn primarily through interactions that are either competitive (i.e., compete to see who achieves the highest grade) or individualistic (i.e., work alone toward a goal). This is supported by studies that revealed $75 \%$ of undergraduate science courses are offered as professor-centered lecture courses $(1,2,14)$ which rely on either competitive and/or individualistic teaching methods. It is often difficult for students who have been conditioned to learn in a competitive and/or individualistic fashion to see the benefits derived from cooperative group interactions. The fourth component of CL, teamwork skills, requires not only providing role models but also presenting opportunities to practice teamwork skills. There are several ways to structure the use of interpersonal and small group skills. We prepare students to work in cooperative groups by explaining to them the process and expectations, emphasizing professional behavior, and demonstrating what is meant by professional behavior and common courtesies. We preassign students to teams and expert roles. We discovered through trial and error that having predetermined team assignments eliminates unprofessional behavior due to personality problems that erupt when a few members of a team previously knew each other and form cliques, or when similar majors are overrepresented leading to problems with competition. We assemble three- or four-member teams in which the students do not know each other, are from different majors, and provide an equal distribution of genders and academic levels.

The final essential component of CL is group processing. In this course, group processing takes place during team meetings, where the members are encouraged to reflect and then plan how to improve the group's progress. The instructor acts as a facilitator during the team meetings, with students taking turns assuming the leadership role as it relates to their expertise. They are given time to evaluate the team's progress toward their Benchmarks and actions and to plan how to overcome obstacles that are impeding their progress. 
TABLE 1. Additional examples of microbial problems and corresponding expert roles

\begin{tabular}{|c|c|}
\hline Microbial problems & Expert roles \\
\hline $\begin{array}{l}\text { "So work makes you ill?" An analysis of microbial, } \\
\text { engineering, and legal aspects of sick building syndrome. }\end{array}$ & $\begin{array}{l}\text { Infectious Disease Specialist, Environmental Engineer, Health } \\
\text { Care Specialist, and Workman's Compensation Attorney }\end{array}$ \\
\hline $\begin{array}{l}\text { "Flying the friendly skies?" An analysis of a potential } \\
\text { microbe-induced health issue associated with reduced levels of } \\
\text { fresh air on commercial airplanes. }\end{array}$ & $\begin{array}{l}\text { Infectious Disease Specialist, Federal Aviation Administration } \\
\text { Economist, Health Care Specialist, and Environmental } \\
\text { Aviation Engineer }\end{array}$ \\
\hline $\begin{array}{l}\text { "Great Day Melissa, Look at the Mess Made by the New } \\
\text { Carissa!" An analysis of Oregon's plan to clean up the recent } \\
\text { controversial oil spill using engineering rather than } \\
\text { bioremediation approaches. }\end{array}$ & $\begin{array}{l}\text { Bioremediation Microbiologist, Environmental Attorney, } \\
\text { Industrial Engineer, Environmental Protection Agency } \\
\text { Economist }\end{array}$ \\
\hline $\begin{array}{l}\text { "Unsolved Mysteries!" An analysis of the spread of hantavirus } \\
\text { and the roles climate conditions and human behavior may play. }\end{array}$ & $\begin{array}{l}\text { Infectious Disease Specialist, Epidemiologist, Wildlife } \\
\text { Biologist, and Public Policy Expert on Climate Conditions }\end{array}$ \\
\hline $\begin{array}{l}\text { "The Perils of Being a College Student (and you thought dead } \\
\text { week was a killer)!" The controversy surrounding bacterial } \\
\text { meningitis outbreaks on college campuses. }\end{array}$ & $\begin{array}{l}\text { Sociologist, Infectious Disease Specialist, Student Center } \\
\text { Health Care Professional, University Dean of Students }\end{array}$ \\
\hline $\begin{array}{l}\text { "BYOB (Bring your own bugs)!" An analysis of the role bug } \\
\text { zappers may play in transmitting microbial pathogens to food. }\end{array}$ & $\begin{array}{l}\text { Infectious Disease Specialist, Entomologist, Manufacturing } \\
\text { Design Engineer, Consumer Safety Advocate }\end{array}$ \\
\hline $\begin{array}{l}\text { "Scrub-a-dub-dub!" The controversy of greenhouse pollutants } \\
\text { and the use of cyanobacterial bioreactors to scrub carbon } \\
\text { dioxide from smokestack emissions. }\end{array}$ & $\begin{array}{l}\text { Industrial Microbiologist, Environmental Engineer, Industry } \\
\text { Public Relations Spokesperson, Environmental Protection } \\
\text { Agency Greenhouse Gases Expert }\end{array}$ \\
\hline
\end{tabular}

Results from evaluations and assessments in this upperdivision problem-solving microbiology course reveal similar conclusions as previously reported in other studies $(4,5$, $7,9-11,13,15)$. These studies revealed that students achieve more, have greater intrinsic motivation to learn, use cognitive processes more, have greater long-term retention of concepts, and discover they enjoy working in teams of diverse students and are productive in this learning environment. The information from assessing and surveying more than 600 students in the MB390 course over an 8-year period are summarized in Tables 2 and 3.

As described in Table 2, assessments revealed a 90\% retention of content per student. Assessments were made one month after the use or presentation of concepts. Short and long answer questions comprised the assessment tool. No advance warning was given that assessments would be administered, thus students did not have an opportunity to "cram" the night before the assessment. Students were asked very specific and detailed questions about a microorganism, including its physiology and genetics, its relationship to humans, its relationship to its environment, and its role in the issue, and about the recommendations made by the presenting team. In addition to assessment data, we also have many, many anecdotal stories relating to retention. For example, we recently talked with a student who had taken MB390 2 years ago. He was a non-SMET major who had never had microbiology before MB390. At the time he was enrolled in MB390, he was considered an academically-at-risk student. He animatedly related to us that he never forgot what he had learned in MB390 about the Monkey B virus and BSL-4 facilities (see Fig. 2A for project description), perfectly recalling details about viral replication, symptoms, containment levels, etc. Furthermore, he emphasized how this course represented the turning point for him with respect to increasing his confidence level when tackling his academic studies. What was truly amazing about this student's recollection was that he had not been on the Monkey B virus team but rather had been on a team charged with making recommendations concerning the controversy of using commercial airlines to transport tissue samples potentially infected with the Ebola virus. Not only could he perfectly recall his own team's research on Ebola and transport procedures and restrictions for potentially infected tissues, he was also able to perfectly recall information presented 2 years ago by other teams, including the controversy of the Monkey B virus and BSL-4 facilities. As an added note, this student, who was initially thought to have a low probability of completing a degree, will be graduating at the end of his fourth academic year.

Additional assessments (Table 2) revealed that $98 \%$ of the students were successful in their expert roles by achieving the grade they set out to receive. Ninety-seven percent of the students did not skip a class or team meeting. They were motivated to attend team meetings and class because they wanted their own team to be successful, and they wanted to learn the science concepts that the other teams were responsible for presenting. One hundred percent of the students contributed useful information and participated in the learnercentered instructional process needed during team meetings and subsequent public presentation and debate, and $100 \%$ of the students participated in the development, delivery, and defense of the team's public presentation.

As revealed in student evaluations of MB390 (Table 3), $95 \%$ of the students surveyed identified that they used problem solving, critical thinking, and analytical skills in this course and that these were skills essential to their future employability. Ninety percent of the students surveyed identified competent communication and teamwork skills as essential for success in the workplace. Yet, less than $20 \%$ of 
the students surveyed indicated that they felt they had enough opportunity to practice communication and teamwork skills before taking the upper-division MB390 course. Ninety-eight percent of the students surveyed stated that this was the first course they had taken in which there was an effective mechanism in place to ensure that all team members contributed equally and fully to the goal of analyzing and solving the assigned team problem. When students were asked in the evaluation (a university-wide evaluation instrument), "as a result of having this instructor, I have learned a significant number of new ideas and or skills," the numerical evaluation for this question was a 3.9 average (on a scale of 0 to 4 , where 0 is low and 4 is high). This high rating indicates that a large percentage of students surveyed felt they learned new ideas and or skills. On a scale of 0 to 4 , where 0 is low and 4 is high, the numerical evaluation of the MB390 course was a 3.9 average. This high rating indicates that the majority of undergraduate students thought very favorably of the course and the instructors.

In addition, numerous personal testimonials have been documented in writing as a result of students' evaluations of this course. These include such statements as "Great course!" "Awesome!" "This is the best class I have taken at OSU-I learned more in this ten weeks than I have in my previous 3 years of college." "I really think your style of teaching is effective-because I have learned more and remembered more than in any other class that I have ever taken!" "Thank you for teaching me skills in research, teamwork, communication, and organization!" "This class has been the most enjoyable class I've taken here at OSU-I've learned more than in any of my lecture classes!" "This class ROCKS!-I learned so much more from this course than from the boring passive routine lecture-test format-more courses should incorporate this learning format!"

The most intriguing data emerging as a result of fully employing the tenets of Cooperative Learning in MB390 resides with the demographics for this course. Approximately 20 to $25 \%$ of the students enrolled are SMET majors, while 75 to $80 \%$ are non-SMET majors, with $50 \%$ of all students identifying teaching at the precollege level as a potential ca-

TABLE 2. Student assessments in MB390

\begin{tabular}{ll}
\hline Criteria of earned success & $\begin{array}{l}\text { Assessment } \\
\text { outcome }(\%)\end{array}$ \\
\hline
\end{tabular}

Retention of concepts and details

Student success in expert roles:

earning the grade they set out to achive

Student attendance in class and team meetings without any absences

Student success in material contribution

Student participation in CL activities

100
TABLE 3. Student evaluations of MB390

\begin{tabular}{|c|c|}
\hline Evaluation criteria & Evaluation outcome \\
\hline $\begin{array}{l}\text { Student self-recognition that they } \\
\text { used problem solving, critical } \\
\text { thinking, and analytical skills }\end{array}$ & $95 \%$ \\
\hline $\begin{array}{l}\text { Student self-recognition that } \\
\text { communication and teamwork } \\
\text { skills were essential components } \\
\text { of success }\end{array}$ & $90 \%$ \\
\hline $\begin{array}{l}\text { Students that considered CL } \\
\text { methods as first effective team- } \\
\text { learning environment in their } \\
\text { academic career }\end{array}$ & $98 \%$ \\
\hline $\begin{array}{l}\text { On a scale of } 0 \text { to } 4 \text { ( } 0 \text { is low, } 4 \\
\text { is high), students felt they had } \\
\text { learned a significant number of } \\
\text { new ideas and skills }\end{array}$ & 3.9 \\
\hline $\begin{array}{l}\text { On a scale of } 0 \text { to } 4 \text { ( } 0 \text { is low, } 4 \\
\text { is high), average student } \\
\text { evaluation of MB390 }\end{array}$ & 3.9 \\
\hline
\end{tabular}

reer choice. The majority of students elect to take this problem-solving, upper-division science course without it fulfilling a science requirement for their degree. Gender is evenly divided, with approximately $49 \%$ of the students female and $51 \%$ male. Yet it is the demographic of diversity that draws attention, especially when one considers the diversity of OSU and the state of Oregon. Undergraduate students underrepresented in science (Hispanic, African American, Native American, Pacific Islander) represent approximately $13 \%$ of the total student population at OSU. This is reflective of the population-at-large residing in the state of Oregon. Yet, students underrepresented in science make up at least $40 \%$ of the students enrolled in MB390.

\section{CONCLUSIONS}

How well are students learning microbiology by this method? The conclusions generated from this course over an 8-year period support those conclusions previously reported in other studies $(4,5,7,9-11,13,15)$, where retention rates exceed $90 \%$ when evaluated by written assessments. In addition, students garner practice in the use of problem solving, critical thinking, integration, and synthesis skills while tackling their microbial problems. They must demonstrate historical and scientific knowledge in one or more disciplines, and they are required to express what they know using both oral and written communication skills. Most importantly, they are given a chance to practice their interpersonal skills through teamwork in a learning environment that has traditionally 
relied on competitive and/or individualistic approaches to teach microbiological concepts. Obstacles can be encountered with CL if all essential components are not properly in place. Negative learning experiences for both students and instructors have arisen in this course when students were allowed to select their own teams or expert roles, when an assumption was made that students knew how to identify and define relevant problems or expertise, when team sizes were larger than four members, when microbial concepts to be learned were vague and poorly defined, when projects did not promote positive interdependence (e.g., duplication in different expert roles), when Benchmark deadlines were not in place or enforced, when individual accountability was inadequately monitored and assessed (i.e., giving group grades instead of grades based on individual contributions), and when the assumption was made that upper-division students have evolved interpersonal skills and thus knew how to use these skills to productively function in team situations. However, when the components of CL are clearly in place, high levels of successful learning can be achieved; retention of material is high and student satisfaction with this learning process is very high. Cooperative Learning may not be suitable for all science content, but it certainly is of value when students are asked to use critical thinking, analysis, integration, and synthesis skills, in addition to communication and teamwork skills. This course enjoys immense popularity at Oregon State University, with a large number of students waiting to get into it. Both honor students and academically-at-risk students experience success, and regardless of their level, they feel they have been challenged in their learning experience. Most importantly, what we have learned through the use of Cooperative Learning is that the stereotypes held by SMET majors and non-SMET majors about each other are dissolved and the barriers that define those who understand the science from those who ignore the science are eliminated.

\section{ACKNOWLEDGMENTS}

J.E.T. acknowledges the enormous support of OSU's academic advisors and coordinators, including but not limited to, Polly Jeneva, Marianne Vydra, Marci Ridpath, Trina Kudlacek, Clara Horne, and numerous College of Science advisors who graciously directed their students to this course during its early experimental years. Furthermore, she acknowledges the participation of former graduate students, such as Wolfgang Ebel, who helped shape the course in its early years. We acknowledge the support of all OSU undergraduate students who have elected to learn microbiology through cooperation. This work was supported in part by a grant from the Dr. H. B. and R. H. Levey Philanthropic Fund awarded to J.E.T.

\section{REFERENCES}

1. American Association for the Advancement of Science. 1993. Benchmarks for science literacy. Oxford University
Press, New York, N.Y.

2. American Association for the Advancement of Science. 1998. Project 2061: science literacy for a changing future. American Association for the Advancement of Science, Washington, D.C.

3. Johnson, D. W., and R. T. Johnson. 1978. Cooperative, competitive, and individualistic learning. J.Res.Dev.Educ. 12:8-15.

4. Johnson, D. W., and R. T. Johnson. 1989. Cooperation and competition: theory and research. Interaction Book Co., Edina, Minn.

5. Johnson, D. W., and R. T. Johnson. 1991. Learning together and alone: cooperation, competition, and individualization, 3rd ed. Prentice Hall, Englewood Cliffs, N.J.

6. Johnson, D. W., and R. T. Johnson. 1992. Positive interdependence: the heart of cooperative learning. Interaction Book Co., Edina, Minn.

7. Johnson, D. W., and R. T. Johnson. 1993. What we know about cooperative learning at the college level. Coop. Learning Mag. Coop. Higher Educ. 13:17-18.

8. Johnson, D. W., R. T. Johnson, and E. J. Holubec. 1994. The nuts and bolts of cooperative learning. Interaction Book Co., Edina, Minn.

9. Johnson, D. W., R. T. Johnson, and E. J. Holubec. 1998. Cooperation in the classroom, 7th ed. Interaction Book Co., Edina, Minn.

10. Johnson, D. W., R. T. Johnson, A. Ortiz, and M. Stanne. 1991. Impact of positive goal and resource interdependence on achievement, interaction, and attitudes. J. Gen. Psychol. 118(4):341-347.

11. Johnson, D. W., R. T. Johnson, and K. A. Smith. 1998. Active learning: cooperation in the college classroom. Interaction Press, Edina, Minn.

12. Lew, M., D. Mesch, D. W. Johnson, and R. T. Johnson. 1986. Positive interdependence, academic and collaborative skills: group contingencies and isolated students. Am. Educ.

Res. J. 23:476-488.

13. Mesch, D., D. W. Johnson, and R. T. Johnson. 1988. Impact of positive interdependence and academic group contingencies on achievement. J. Social Psychol. 28:845-852. 14. National Science Foundation. 1996. Indicators of science and mathematics education in 1995. National Science Foundation, Arlington, Va.

15. Slavin, R. E. 1991. Synthesis of research on cooperative learning. Educ. Res. 4:67-77.

16. Slavin, R. E 1993. What post secondary cooperative learning learns from elementary and secondary research. Coop. Learning Coll. Teaching 4:2-3.

17. Trempy, J. E. 2000. Building teams of diverse students to cooperatively solve problems of microbial origin. Focus Microbiol. Educ. 6(3):7-9. 